\title{
A Recurrent Giant Pilomatricoma on the Back
}

\author{
Jin Seok Kang ${ }^{1}$, Min Sung Tak ${ }^{1}$, Sang Gue Kang ${ }^{1}$, So Young Jin ${ }^{2}$ \\ Departments of ${ }^{1}$ Plastic and Reconstructive Surgery and ${ }^{2}$ Pathology, Soonchunhyang University Hospital, Soonchunhyang University College of Medicine, \\ Seoul, Korea
}

No potential conflict of interest relevant to this article was reported.

Pilomatricoma is a relatively rare, slow-growing neoplasm of the skin. The term "pilomatrixoma," was proposed in 1961 by Forbis and Helwigto refer to its origin from hair matrix cells. The tumor occurs anywhere in the body that contains hair follicles but is generally located on the head, neck and upper extremities. It is less than $2 \mathrm{~cm}$ in diameter and scarcely recurs under the completely excised state [1]. When the mass is greater than $5 \mathrm{~cm}$, the term "giant pilomatricoma" is used. The low incidence and clinical spectrum often results in misdiagnosis, and most are confirmed only after histological evaluation. In this report, we present a case of recurrent giant pilomatricomaof the back and review the literature on this rare clinical entity.

In 2011, a 33-year-old man was admitted to our clinic complaining of a palpable, slowly growing mass on his back. Previously, the patient had undergone an excisional operation about 3 years ago at an outside hospital, with subsequent recurrence, which prompted him to seek further care. Otherwise, his past medical history was unremarkable. Examination revealed a $5 \times 4$ $\mathrm{cm}$ sized subcutaneous irregular, hard, mobile mass in right lumbar area (T12 to L2). There was no ulceration, skin change, or tenderness. An excisional operation was performed, and the histo-

\section{Correspondence: Min Sung Tak}

Department of Plastic and Reconstructive Surgery, Soonchunhyang University Hospital, Soonchunhyang University College of Medicine, 53 Daesagwan-ro, Yongsan-gu, Seoul140-743, Korea

E-mail: tarkms@schmc.ac.kr

*This article contains supplemental Table S1.

*This work was supported by Soonchunhyang University Research Fund.

Received June 30, 2014 / Revised July 23, 2014 / Accepted August 1, 2014 logic finds were consistent with pilomatricoma.

During the ensuing year, the mass returned with a relatively accelerated growth in the few months leading up to a second clinical visit (Fig. 1). Examination revealed an $11 \times 12 \mathrm{~cm}$ mass which had similar physical characteristics to the mass excised at the secondary operation. The skin overlying the mass was intact, but appeared reddish. A magnetic resonance imaging (MRI) of the region revealed a $4 \times 9 \times 10 \mathrm{~cm}$ mass which was well-circumscribed without involvement into adjacent tissue planes. It had an intermediate T1-weighted signal intensity, high T2-weighted signal intensity, and heterogeneous enhancement (Fig. 2).

The third operation incorporated the resection of a wide mar-

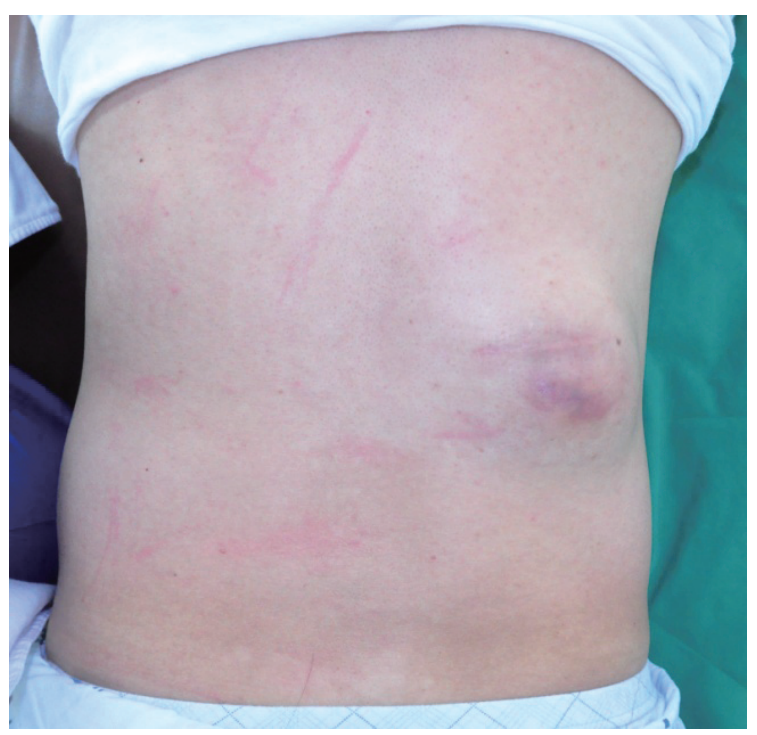

Fig. 1. Photo of the right lumbar mass with bluish discoloration. 
gin of the adherent skin as well as the mass itself. The resulting defect was covered with a local advancement flap (Fig. 3). Again, histopathological analysis was consistent with pilomatricoma. The tissue contained irregular epithelial islands embedded in a cellular stroma, which consisted of basophilic basaloid cells and anucleate squamous cells (ghost cells) (Fig. 4).

Pilomatricomas are slow-growing, firm, painless, superficial neoplasms. Rarely, some reddish or bluish discoloration arenoted, when the tumor grows more superficial or when there is underlying hemorrhage. It may appear at any age, with a bimodal peak in
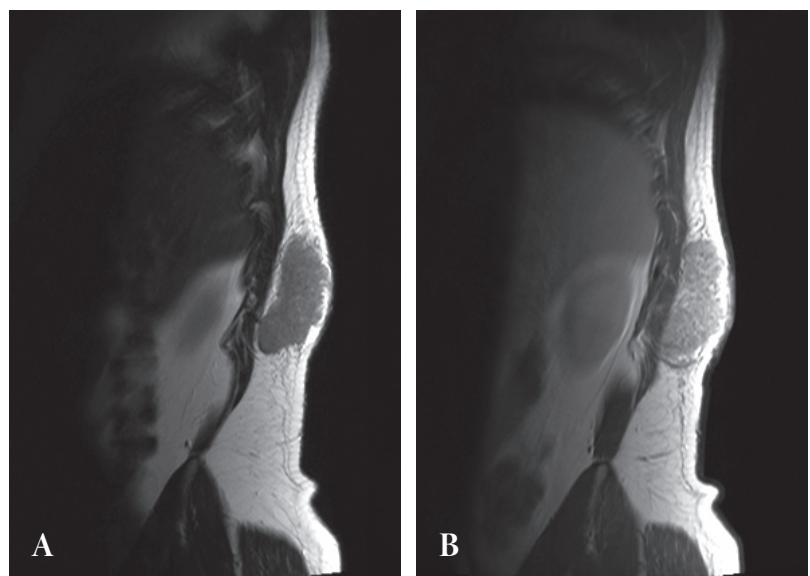

Fig. 2. Magnetic resonance imaging images of the lumbar mass. (A) T2 weighted image. (B) T1 weighted image.

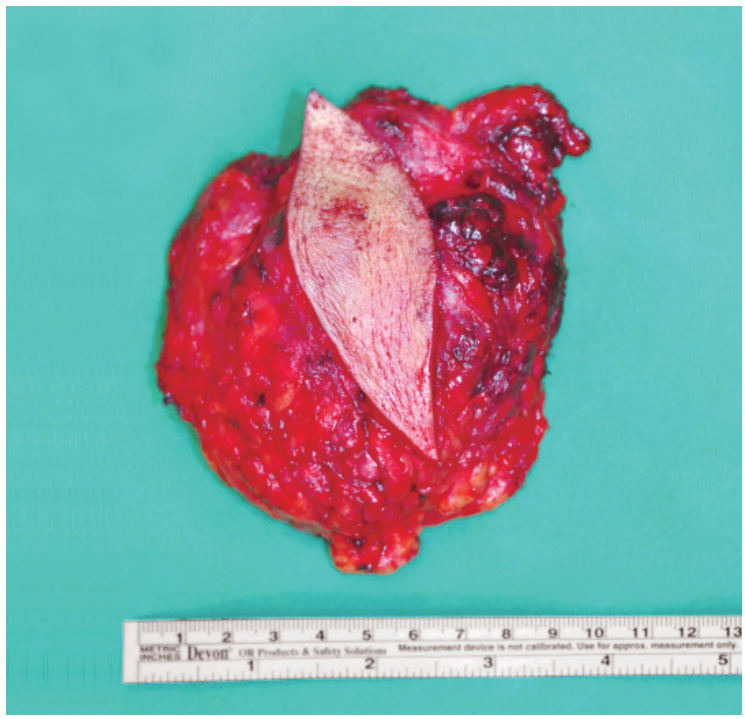

Fig. 3. Intraoperative specimen.

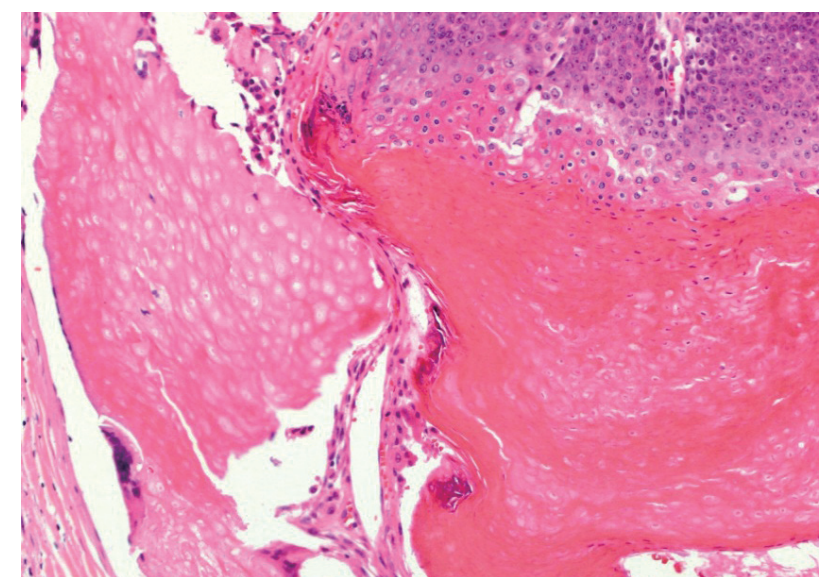

Fig. 4. Epithelial islands consist of basaloid cells and anucleate epithelial cells (ghost cells) (H\&E, ×200).

the first and sixth decades. The female to male ratio is 1.5:1 overall, but this ratio is higher at 2.5:1 for patients younger than 20 years [1]. The tumors are generally located on the head (51.5\%), neck and upper extremities. Since the tumor cells originate from hair matrix cells, these lesions do not occur and have never been reported among tumors of palms and soles. Complete excision is curative, and recurrent rate is close to zero percent when completely excised.

The clinical diagnosis of pilomatricoma is difficult because of its rare occurrence and varying clinical presentation. Julian and Bowers reported that only $21 \%$ of pilomatricoma tumors were diagnosed correctly at the initial time of diagnosis, with the most common misdiagnosis being epidermal cyst (38\%) [1]. MRI is useful in differentiating pilomatricomas from other tumors. The tumor usually appears heterogeneous on T2 weighted image (T2WI) and on post-enhancement T1WI. Specifically, T2WI images are able to differentiate areas of calcification versus keratin (high versus low signal, respectively) [2].

While most epithelial skin tumors appear as a nodule with semitransparent epidermis and are benign, pilomatricomas do not spontaneously regress and can develop into a locally-aggressive entity that tends to recur but with a low metastatic potential [3]. Imaging studies and fine needle aspiration cannot assure definite diagnosis in atypical cases. In giant pilomatricomas, it is difffcult to distinguish benign and malignant tumors without a definitive surgical specimen. Because of this uncertainty, giant 
pilomatricomas should be resected with the same margin (1-2 $\mathrm{cm}$ ) used if preoperative examination cannot rule out the possibility of malignancy [4]. When fixed to skin, some authors recommend that the tumor be excised with the adherent skin, as was the case with our patient at third operation [5].

Our review has identified a total 43 cases of giant pilomatricomas (Supplemental Table S1). The tumors range from 5 to $20 \mathrm{~cm}$, with the peak age of presentation in second and sixth decades. Head and neck (23/43) was the most common site, followed by upper extremities (11/43), trunk (6/43), and lower extremities (3/43).

Supplemental Table S1. Case reports of giant pilomatricomas Supplemental data can be found at: http:// www.e-acfs.org.

\section{REFERENCES}

1. Julian CG, Bowers PW. A clinical review of 209 pilomatricomas. J Am Acad Dermatol 1998;39:191-5.

2. Hsieh TJ, Wang CK, Tsai KB, Chen YW. Pilomatricoma: magnetic resonance imaging and pathological evaluation. J Comput Assist Tomogr 2008;32:320-3.

3. Allaoui M, Hubert E, Michels JJ. Malignant pilomatricoma: two new observations and review of the relevant literature. Turk Patoloji Derg 2014;30:66-8.

4. Yamauchi M, Yotsuyanagi T, Saito T, Ikeda K, UrushidateS, Higuma Y. Three cases of giant pilomatrixoma--considerations for diagnosis and treatment of giant skin tumours with abundant inner calcification present on the upper body. J Plast Reconstr Aesthet Surg 2010;63:e51924.

5. Yoshimura Y, Obara S, Mikami T, Matsuda S. Calcifying epithelioma (pilomatrixoma) of the head and neck: analysis of 37 cases. Br J Oral Maxillofac Surg 1997;35:429-32. 